\title{
PENINGKATAN KETERAMPILAN PROSES SAINS DALAM PEMBELAJARAN IPA SISWA KELAS V SD PERTIWI MAKASAR
}

\author{
Amri Amal $^{1^{*}}$, Fajri Basam $^{2}$, Rizal $^{3}$ \\ 1,2Program Studi Pendidikan Sekolah Dasar, Fakultas Keguruan dan Ilmu Pendidikan \\ Universitas Muhammadiyah Makassar, Indonesia \\ ${ }^{3}$ Sekolah Dasar Pertiwi Makassar, Indonesia \\ *Korespondensi. E-mail: dikdaspgsd_amri@yahoo.com
}

\begin{abstract}
Abstrak
Penelitian ini bertujuan untuk menganalisis penigkatan keterampilan proses sains siswa kelas V. Penelitian ini adalah penelitian tindakan kelas yaitu sebuah kegiatan penelitian yang dilakukan di kelas sebagai upaya untuk mengkaji, merefleksi secara kritis suatu rencana pembelajaran terhadap kinerja (Performance) guru, interaksi guru dengan siswa, serta interaksi siswa dengan kelas. Secara garis besar terdapat empat tahapan, yaitu (1) perencanaan, (2)pelaksanaan, (3) pengamatan (observasi), dan (4) refleksi. Peningkatan keterlaksaan proses pembelajaran di kelas dari siklus I dengan nilai rata-rata 1.43 dengan kategori terlaksana seluruhnya, dan pada siklus II dengan nilai rata-rata 1.58 dengan kategori terlaksna seluruhnya.
\end{abstract}

Kata Kunci: Keterampilan Proses, Siswa Kelas V

\section{IMPROVING SKILLS OF SCIENCE PROCESSES IN SCIENCE LEARNING IN CLASS V STUDENTS}

\begin{abstract}
This study aims to analyze the improvement of science skills in class students. This research is classroom action research, namely a research activity carried out in the classroom as an effort to assess, critically reflect on a learning plan on teacher performance (Performance), teacher interaction with students, and student interaction with the class. Broadly speaking there are four stages, namely (1) planning, (2) implementation, (3) observation (observation), and (4) reflection. Increasing the learning process in the classroom from the first cycle with an average value of 1.43 with the category fully implemented, and in the second cycle with an average value of 1.58 with the category fully implemented.
\end{abstract}

Keywords: Process skills, Grade V Students

Copyright $\odot 2019$, JRPD, ISSN 2615 - 1723 (Print), ISSN 2615 - 1766 (Online 


\section{PENDAHULUAN}

Sains (science) merupakan konsep pembelajaran alam dan mempunyai hubungan yang sangat luas terkait dengan kehidupan manusia. Pembelajaran sains (science) sangat berperan dalam proses pendidikan dan juga perkembangan Teknologi. Tujuan penting dalam pembelajaran IPA adalah bagaimana melibatkan siswa dalam penyelidikan dengan mengintegrasikan keterampilan, pengetahuan dan sikap untuk pemahaman konsep-konsep IPA (Zeidan \& Jayosi, 2014). Sama halnya Ali, et al (2013) mengunkapkan, Pembelajaran IPA merupakan cara ideal untuk memperoleh keterampilan dan dan pengembangan konsep yang berkaitan dengan kehidupan sehari-hari.

Studi Internasional yang dilakukan oleh Trends in International Mathematics Science Study (TIMSS) dan PISA (Programme for International Student Assessment) yang diselenggarakan menempatkan Indonesia di posisi bawah dalam daftar negara dari segi kualitas pendidikan dengan berada pada tahapan terendah (Low International Brenchmark) yaitu dibawah skor rata-rata. Hasil penelitian Rusilowati dan Basam (2017) di beberapa sekolah di sulawesi selatan memperkuat bahwa pembelajaran IPA di Indonesia, masih sangat kurang pada aspek keterampilan proses sains siswa dengan ratarata perolehan nilai siswa yaitu 41 dari skor maksimal 100.

Permanasari (2010) mengatakan, pada umumnya pembelajaran IPA di Indonesia menekankan pada tingkat hafalan tanpa diikuti dengan pemahaman yang bisa diterapkan siswa pada kehidupan nyata. Transfer pengetahuan dari guru ke siswa sebagian besar disampaikan dengan mendengarkan penjelasan ataupun ceramah mengenai suatu konsep yang bersifat abstrak sehingga siswa sulit untuk memahami konsep tersebut. Lilinasari

Kemendikbud (2013) menyatakan dalam pelaksanaan pembelajaran IPA terdapat enam pertimbangan yang harus diperhatikan yaitu: (1) empat pilar pendidikan (belajar untuk mengetahui, belajar untuk berbuat, belajar untuk hidup dalam kebersamaan, dan belajar untuk menjadi diri-nya sendiri), (2) inkuiri IPA, (3) Konstruktivisme, (4) sains (IPA), lingkungan, teknologi, dan masyarakat (Salingtemas), (5) penyelesaian Masalah, (6) pembelajaran IPA yang bermuatan nilai. Untuk mewujudkan tujuan pendidikan sains modern menuju abad 21 maka pembelajaran IPA secara tradisional harus diubah menjadi pembelajaran layaknya siswa berpikir seperti ilmuwan dengan melibatkan siswa dalam penyelidikan, pemodelan, dan penalaran yang kompleks yang berkontribusi untuk mengembangkan pemikir kritis masa depan (Crawford, 2016).

Pendidikan Ilmu Pengetahuan Alam (IPA) merupakan bagian dari pendidikan umum yang diharapkan dapat digunakan sebagai sarana pencapaian tujuan pendidikan bangsa. Pendidikan IPA menekankan pada pemberian pengalaman langsung untuk mengembangkan kompetensi agar siswa mampu menjelajahi dan memahami alam sekitar secara ilmiah. Pendidikan Ilmu Pengetahuan Alam (IPA) mengarahkan siswa untuk melakukan penyelidikan sehingga siswa dapat memperoleh pemahaman yang lebih mendalam tentang alam dengan memadukan antara pengalaman proses sains dan pemahaman produk sains dalam bentuk pengalaman langsung.

Keterampilan proses sains merujuk kepada karakteristik kegiatan dan proses ilmiah untuk mendapatkan pengetahuan termasuk konvensi dan etika yang terlibat dalam pengembangan, penerimaan, dan kegunaan pengetahuan ilmiah (Schwartz et al., 2004). Keterampilan proses sains adalah proses bagaimana para ilmuwan bekerja dan bagaimana pengetahuan ilmiah yang dihasilkan dibentuk dan diterima (Lederman, et al., 2014). Keterampilan proses sains merupakan pusat proses dari ilmu pengetahuan yang menjadi sarana ilmu pengetahuan (layaknya para ilmuwan memperoleh data) dan menjadi 
penjelasan tujuan ilmu pengetahuan, layaknya ilmuwan menggunakan data (OECD, 2013).

Pembelajaran keterampilan proses sains penerapanya dalam pembelajaran meliputi 5 (lima) pengalaman belajar yaitu: Mengamati (observing), Menanya (questioning), Mengumpulkan informasi (experimenting), Menalar/Mengasosiasi (associating), dan Mengomunikasi-kan (communicating) (Permendikbud Nomor 58 Tahun 2014). Dalam pembelajaran Keterampilan proses sains dirancang dengan kengiatan atau penyelidikan yang berpusat kepada siswa, yang biasanya berfokus kepada kegiatan inkuirinya bukan diprioritaskan kepada hasilnya (Kelly, 2016). Dalam perancangan inkuiri dapat dilakukakan dengan pertimbangkan: (1) pemilihan fenomena, (2) Pengembangan model, (3) pengembangan bukti, dan (4) membutuhkan kedisiplinan yang baik.

\section{METODE}

Berdasarkan permasalahan yang diteliti, peneliti mengambil jenis penelitian tindakan kelas yaitu sebuah kegiatan penelitian yang dilakukan di kelas sebagai upaya untuk mengkaji, merefleksi secara kritis suatu rencana pembelajaran terhadap kinerja (Performance) guru, interaksi guru dengan siswa, serta interaksi siswa dengan kelas. Secara garis besar terdapat empat tahapan, yaitu (1) perencanaan, (2)pelaksanaan, (3) pengamatan (observasi), dan (4) refleksi.

\section{HASIL DAN PEMBAHASAN}

\section{Deskripsi Keterampilan Proses Sains}

Observasi keterampilan proses dilakukan kepada 35 orang siswa kelas V SD Pertiwi Makassar. Observasi ini dilakukan selama pembelajaran siklus I dan siklus II, untuk mengetahui peningkatan aktivitas keterampilan proses yang dimiliki oleh siswa secara komprehensif. Ringkasan hasil pengamatan aktivitas ditunjukkan pada Gambar2



Gambar 2.Aktivitas Keterampilan Proses 


\section{Deskripsi Hasil Observasi Keterlaksanaan}

Pengamatan terhadap aktivitas guru dan siswa dilakukan pada setiap proses pembelajaran siklus I dan siklus II yaitu masingmasing siklus diadakan empat kali pertemuan.
Dengan demikian dilakukan delapan kali pengamatan pada masing-masing aktivitas guru dan siswa dalam pembelajaran. Adapun ringkasan analisis hasil pengamatan aktivitas guru ditunjukkan pada Gambar 3.

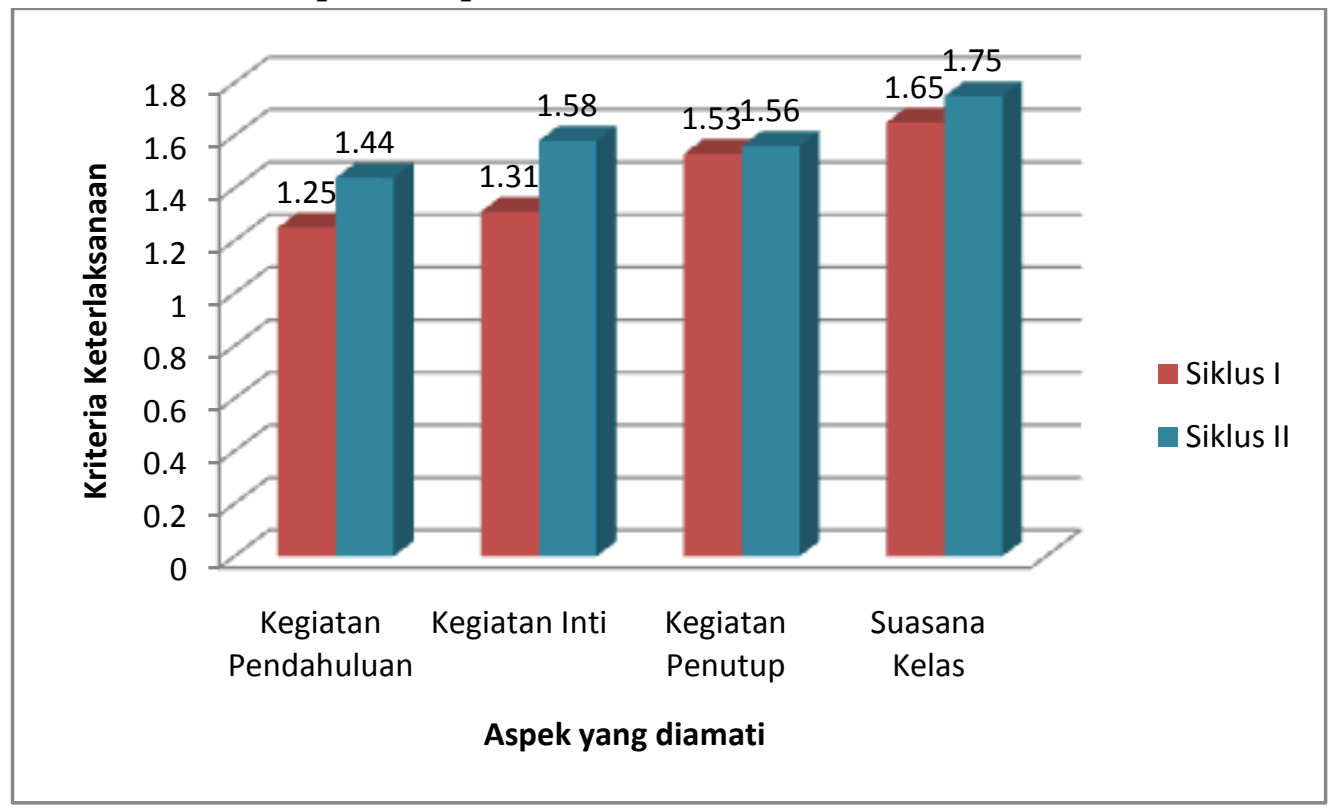

Gambar 3. Hasil Observasi Aktivitas Guru

Dari data tersebut dapat dinyatakan terjadi penigkatan keterlaksaan proses pembelajaran di kelas dari siklus I dengan nilai rata-rata 1.43 dengan kategori terlaksana seluruhnya, dan pada siklus II dengan nilai ratarata 1.58 dengan kategori Terlaksna seluruhnya.

\section{Pembahasan}

Berdasarkan deskripsi, analisis dan refleksi dari proses pembelajaran pada konsep gaya magnet dengan penerapan pendekatan keterampilan proses pada setiap siklus yang telah dilakukan, peneliti dapat menyimpulkan hasil dari kegiatan tersebut terdapat pada temuan-temuan esensial dalam penelitian yang telah dilaksanakan. Temuan temuan esensial tersebut merupakan hasil yang sangat penting dari penelitian yang dilaksanakan, untuk di bahas dan dicari penyebab serta untuk mengambillangkah-langkah tindakan yang yang tepat untuk perbaikan-perbaikan pada rencana selanjutnya dalam pembelajaran.

Berhasil tidaknya suatu proses pembelajaran ditentukan oleh faktor guru, siswa dan media/alat pembelajaran. Selama pelaksanakan siklus I, siklus dan II, ditemukan bahwa ketepatan guru dalam membuat RRP akan menjadi arah pembelajaran untuk mencapai tujuan, dengan demikian saat guru mengajar di kelas akan tercipta suatu pembelajaran yang dinamis. Maka guru dapat memberikan siswa pengalaman belajar yang menarik dan bermakna. Lilinasari (2010: 194) menyatakan pembelajan IPA selalu bertolak dari hubungan sebab-akibat, artinya siswa mulai diperkenalkan dengan pola berpikir causal-effect yang terdapat dalam gejala alam, yang diawali dengan kemampuan mengamati dari pengalaman langsung dan pengalaman tak langsung. Pembelajaran IPA harus melibatkan 
siswa pada pengalaman yang dikenal dengan istilah hands-on sehingga terjadi minds-on.

Prakteknya pelaksanaan siklus I, dan II menemui berbagai kendala yaitu dalam keterampilan bertanya dan mengamati, namun semua itu dapat diatasi, guru memberikan motivasi kepada siswa agar mereka tidak merasa bosan dalam pembelajaran IPA. Tujuan akhir dari pembelajaran IPA adalah untuk menghasilkan individu yang mampu memahami dan mengevaluasi informasi dalam membuat suatu keputusan serta lebih jauh lagi untuk menghasilkan individu dengan keterampilan profesional yang berbasis ilmu pengetahuan (Duschl, et al., 2007: 34).

Melalui pembelajaran IPA dapat memberikan tiga macam keterampilan dan pemahaman sains bagi para siswa yaitu prinsipprinsip dan konsep-konsep sains, mendapatkan keterampilan menalar dan melakukan prosedur kerja ilmuwan sains, serta memahami sifat alami sains sebagai bentuk tertentu dari usaha keras manusia (National Research Council, 2000). Oleh karena itulah dalam pembelajaran IPA diperlukan pendekatan kerja ilmiah dengan dukungan pembelajaran berbasis penyelidikan. Ternyata pembelajaran IPA dengan menggunakan keterampilan proses membuat pembelajaran aktif, kreatif dan menyenangkan. Karena di sini siswa tidak hanya mendengarkan penjelasan dari guru, tetapi mereka diberi kesempatan untuk melakukan keterampilan proses. Dan terlihat dari siklus I, dan siklus II siswa penigkatan keterampilan proses belajar siswa semakin meningkat.

Adapun kelebihan dalam pembelajaran berlangsung: 1) tepat waktu dalam mengajar, sehingga dapat meningkatkan aktivitas belajar siswa baik secara kognitif dan fisik; 2) dengan adanya alat peraga yang digunakan dapat meningkatkan pemahaman siswa terhadap materi yang diajarkan; 3) memberikan kesempatan siswa untuk menemukan dan menerapkan ide-ide yang ada pada diri siswa dalam menyelesaikan soal yang diberikan; 4) dengan adanya kerja kelompok yang dilakukan dapat mengembangkan hubungan interpersonal dalam mengerjakan soal dengan teman kelompoknya. Yang perlu ditingkatkan dalam mengajar: 1) perlu ditingkatkan dalam hal kedisiplinan siswa pada saat proses pembelajaran berlangsung sehingga kelas tidak menjadi gaduh/ribut; 2) sebaiknya setelah siswa selesai melaksanakan percobaan (misalnya: rangkaian listrik) salah satu dari kelompok tersebut seharusnya memperagakan hasil praktek yang dilakukan di depan temantemanya.

Keterampilan proses sains adalah pembelajaran yang menekankan pada proses belajar, aktivitas dan kreativitas peserta didik dalam memperoleh pengetahuan, keterampilan, nilai dan sikap, serta menerapkan dalam kehidupan sehari-hari(Acesta, 2014). Keterampilan proses sains dalam pembelajaran siswa yaitu untuk memberikan kesempatan kepada anak untuk belajar melalui penyelidikan dengan aturan-aturan dan bimbingan yang diberikan (Kelly, 2016).

Pembelajaran IPA terpadu dapat menjadikan siswa memperoleh pengalaman secara langsung melalui konsep yang depelajari secara menyeluruh (holistik), bermakna, otentik, dan aktif (Permanasari, 2010). Dalam pelaksanaanya pembelajaran IPA tidak diajarkan secara terpisah sebagai mata pelajaran lainnya tetapi diajarkan secara menyeluruh atau terpadu. . Wisudawati dan sulistyowati (2014) menjelaskan bahwa konsep IPA memerlukan penalaran dan proses mental pada seseorang siswa yang merupakan kemampuan mengintegrasikan pengetahuan/skema kognitif siswa yang tersusun dari atribut-atribut dalam bentuk keterampilan dan nilai untuk mempelajari fenomena-fenomena alam.

\section{SIMPULAN}

Berdasarkan hasil penelitian yang telah dilakukan, maka dapat disimpulkan bahwa penerapan keterampilan proses sains pada siswa kelas $\mathrm{V}$ mampu mendorong siswa untuk aktif dalam mengamati, bertanya, melakukan percobaan, mengkomunikasikan, dan 
menyimpulkan. Penigkatan keterampilan proses tersebut searah dengan peningkatan keterlaksanaan pembelajaran IPA di kelas.

\section{DAFTAR PUSTAKA}

Acesta, A. (2014). Penerapan Pendekatan Keterampilan Proses Sains Untuk Meningkatkan Hasil Belajar Siswa Dalam Pembelajaran IPA. Jurnal Pendas, 1(2).

Ali, L.U., Suastra, I.W., \& Sudiatmika, A.A.I.A.R. (2013). "Pengelolaan Pembelajaran IPA Ditinjau Dari Hakikat Sains Pada SMP di Kabupaten Lombok Timur". e-Journal Program Pascasarjana Universitas Pendidikan Ganesha Program Study IPA. 3(1).

Crawford, B. A. (2016). Supporting Teachers in Inquiry/Science Practices, Modeling, and Complex Reasoning in Science Classrooms. https://www.researchgate.net/profile/ Barbara_Crawford2/publication/29099 6573_Title_Supporting_Teachers_in_In quiryScience_Practices_Modeling_and_ Complex_Reasoning_in_Science_Classr ooms/links/569d4a5608aed27a702f9ec 9.pdf (diunduh 23 Oktober 2018).

Depdiknas. (2006). Panduan Pengembangan Pembelajaran IPA Terpadu. Jakarta: Puskur-Balitbang.

Duschl, R. A., Schweingruber, H. A., \& Shouse, A. W. (Eds.). (2007). Taking Science to School: Learning and Teaching Science in Grades K-8. National Academies.

Kelly, G. J. (2016). Inquiry Learning and Teaching in Science Education. https://www.researchgate.net/profile/ Gregory_Kelly3/publication/30474802 7_Inquiry_Learning_and_Teaching_in_ Science_Education/links/57793b4c08a eb9427e2bfd97.pdf

Kemendikbud. (2013). Ilmu Pengetahuan Alam SMP/MTs Kelas VII. Jakarta:Politeknik Negeri Media Kreatif.
Kemendikbud. (2014). Permendikbud Nomor 58 Tahun 2014 Tentang Kurikulum 2013 Sekolah MenengahPertamal Madrasah tsanawiyah. Jakarta: Menteri Pendidikan dan Kebudayaan Republik Indonesia.

Lederman, J. S., Lederman, N. G., Bartos, S. A., Bartels, S. L., Meyer, A. A., \& Schwartz, R. S. (2014). "Meaningful Assessment of Learners' Understandings About Scientific Inquiry-The Views About Scientific Inquiry (VASI) Questionnaire". Journal of Research in Science Teaching, 51(1): 65 83.

Liliasari. (2010). "Pengembangan Keterampilan Berpikir melalui Pembelajaran Sains menuju Masa Depan " dalam Hidayat, T., Kaniawati, I., Suwarna, R. I., Setiabudi, A., \& Suhendra. Teori, Paradigma, Prinsip dan Pendekatan Pembelajaran MIPA dalam Konteks Indonesia. Bandung: JICAFMIPA UPI.

Martin, M.O., Mullis, I.V.S., Foy, P., \& Stanco, G.M. (2012). TIMSS 2011 International Results in Science. Chestnut Hill: TIMSS \& PIRLS.

OECD. (2013). PISA 2012 Assessment and Analytical Framework: Mathematics, Reading, Science,Problem Solving and Financial Literacy. OECD Publishing.

OECD. (2014). PISA 2012 Results in Focus What 15-Year-Olds Know and What They Can Do with What They Know. OECD Publishing.

Permanasari, A. (2010). "Membangun Keterkaitan antara Mengajar dan Belajar Pendidikan Sains SMP untuk Meningkatkan Science Literacy Peserta didik" dalam Hidayat, T., Kaniawati, I., Suwarna, R. I., Setiabudi, A., \& Suhendra, Teori, Paradigma, Prinsip dan Pendekatan Pembelajaran MIPA dalam konteks Indonesia. Bandung: JICAFMIPA UPI.

Rusilowati, A \& Basam, F. (2017). "The Profile of Scientific Literacy Skills Junior High

Copyright O2019, JRPD, ISSN 2615 - 1723 (Print), ISSN 2615 - 1766 (Online 
School Students in Soppeng South Celebes". Proceedings. The 3rd International Seminar on Educational Tecnology 2017 (ISET 2017).

Schwartz, R. S., Lederman, N. G., \& Crawford, B. A. (2004). Developing views of Nature of Science in an Authentic Context: An Explicit Approach to Bridging The Gap Between Nature of Science and Scientific Inquiry. Science Education, 88(4): 610-645.

Wisudawati, A.W. \& Sulistyowati, E. (2014). Metodologi Pembelajaran IPA. Jakarta: Bumi Aksar.

Zeidan, A. H., \& Jayosi, M. R. (2015). Science Process Skills and Attitudes Toward Science among Palestinian Secondary School Students. World Journal of Education, 5(1): 13. 